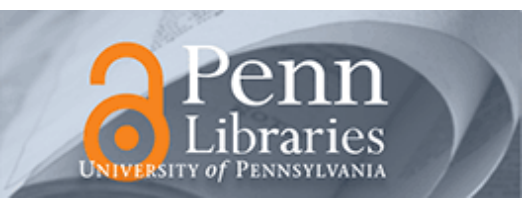

Working Papers in Educational Linguistics

(WPEL)

Volume 17

Number 1 Fall 2001

Article 2

Fall 2001

\title{
Constructing a Multicultural National Identity: South African \\ Classrooms as Sites of Struggle Between Competing Discourses
}

Keith Chick

University of Natal, South Africa

Follow this and additional works at: https://repository.upenn.edu/wpel

Part of the Education Commons, and the Linguistics Commons

\section{Recommended Citation}

Chick, K. (2001). Constructing a Multicultural National Identity: South African Classrooms as Sites of Struggle Between Competing Discourses. 17(1), Retrieved from https://repository.upenn.edu/wpel/vol17/ iss $1 / 2$

This paper is posted at ScholarlyCommons. https://repository.upenn.edu/wpel/vol17/iss1/2

For more information, please contact repository@pobox.upenn.edu. 
Constructing a Multicultural National Identity: South African Classrooms as Sites of Struggle Between Competing Discourses 


\title{
Constructing a Multicultural National Identity: South African Classrooms as Sites of Struggle Between Competing Discourses
}

\author{
Keith Chick \\ Linguistics Programme \\ University of Natal \\ South Africa
}

\begin{abstract}
This article reports on aspects of an ethnographic study carried out in six newly integrated schools in post-apartheid South Africa. It presents evidence that these schools are sites of struggle between competing discourses that construct, maintain, and change social identities in those communities and the wider society. It suggests that South Africa's former limited bilingual policies and current multilingual language policies together with discourses at the micro-level that are congruent with them serve to construct quite different South African national identities: hegemonic, exclusive, and conflicted on the one hand, and egalitarian and inclusive on the other. Finally it speculates on the outcome of the struggle between the competing discourses effects on the prospects of South Africans being able to negotiate a truly multicultural national identity.
\end{abstract}

$\mathrm{I}$ am honored to have been invited to give this lecture. ${ }^{1}$ More important I am grateful for the opportunity it gives me to acknowledge the debt I owe to Nessa Wolfson. She was, in a fairly short period of our acquaintance, a wonderful mentor and friend.

Our acquaintance dates back to her reviewing an article I submitted in the early 1980s to the journal Language in Society entitled "The interactional accomplishment of discrimination in South Africa" (Chick 1985). Because she found it of interest, she introduced herself to me at an international conference, and invited me to visit Penn to discuss my research with her colleagues and students. Nessa subsequently visited South Africa where she had been invited to give a featured address on the subject of intercul-

${ }^{1}$ This paper was given as the 10th Annual Nessa Wolfson Colloquieum in November 2000. 
tural communication. I well recall that address. This is not only because of its excellent quality, but because, shortly after its conclusion, the conference chair interrupted the proceedings to share the dramatic news that the ANC had been unbanned, and that Nelson Mandela's release was imminent.

Nessa and I shared a number of research goals. Amongst the more important of was the better understanding of the relationship between what takes place in the discourse of everyday interactions and the wider social and policy contexts in which these interactions occur. Driven by the hope that our findings would be useful to policy makers and ordinary citizens alike, we sought evidence to support our intuition that what takes place in everyday conversational interactions is more important than was popularly believed or acknowledged in the literature of the social sciences at that time. Our research showed that macro structural phenomena such as government policies powerfully constrain what takes place in the micro contexts of everyday interactions i.e. they constrain the content and form of the discourse and how it unfolds. What I suspect Nessa found of particular interest in my article is my suggestion that such discourse also helps to sustain the structural conditions of the society in question. I suggested in the article that repeated intercultural miscommunication in apartheid South Africa contributed to negative cultural stereotypes. I suggested further that, by providing a justification or rationalization for discrimination, such stereotypes helped sustain the social barriers and power asymmetries that made it difficult in the first place for people in South Africa to learn one another's culturally diverse ways of communicating.

The exploration of how discourses (Discourses) serve to construct, sustain and change institutional and societal structures has remained a strong interest for me in the years since then. This has been stimulated considerably by my first-hand experience of the dramatic socio-political changes accompanying the demise of apartheid South Africa, and the birth and growth of a non-racial democracy there. I found that it is in just such situations of flux and rapid structural change that the role of discourse in constructing, maintaining, and eroding structures becomes easier to observe.

To illustrate, I will report on a study I carried out recently together with Sandra McKay in six newly integrated schools in the Durban metropolitan area of the KwaZulu-Natal province of South Africa. I will focus, in particular, on evidence that these schools are sites of struggle between competing discourses that construct, maintain, and change social identities in those communities and the wider society. I will contrast South Africa's new multilingual/multicultural language policies with the policies they supplanted. I will suggest that such policies, together with discourses at the micro-level (i.e. in schools and classrooms) that are congruent with them, have the potential to construct quite different national identities from those constructed in the past. I will provide details of three of the most pervasive discourses we observed in these schools, and relate these to language-in-education policies and the South African national identities they putatively construct. 


\section{The notion of social identity}

It will be apparent from this description that by discourse I mean more than what Gee (1996:127) describes as "connected stretches of language that make sense." I have in mind what he, to distinguish it from this other sense of discourse, refers to as Discourse (with upper case D) i.e. ways of using language and other means of expression to construct social identities and social relations of power (of which discourse - lower case $d$ - is only a part).

My view of discourse and its role is strongly influenced by conflict theory. Conflict theory rejects the functionalist view that dominated sociolinguistics until recently. According to functional theory society is typically in a state of equilibrium, though this is occasionally disrupted by conflict. Such a view does not square with my South African experience. Conflict theory, by contrast, views groups as constantly in conflict, with dominant groups seeking to build and maintain their hegemony, and subordinate groups seeking to wrest power from them. While acknowledging that power is often exercised coercively, conflict theory focuses on the ideological exercise of power through discourse: "the manufacture of consent to or at least acquiescence towards" the dominant groups' hegemony (Fairclough 1989:4). Discourse analysts who accept this conflictual view of society argue that the discourse conventions associated with particular institutions embody assumptions about social identities and relations within the institutions and/or the society at large. They explain, further, that dominant groups establish and sustain their hegemony by means of ideological strategies (see Thompson 1990) such as:

- projecting their discourse conventions and the assumptions implicit in them as commonsensical, natural or appropriate (i.e. naturalising their own discourse); and

-stigmatising the discourse conventions of subordinate groups.

Such exercising of power may or may not be conscious or intentional. As Davies and Harré (1990:44) point out, what is critical in judging whether or not particular discourses are objectionable, is not whether speakers in the past or present intend their speaking to disempower, but whether it can be shown that in the past they had this effect, even if unintended.

Individuals and groups that do not share these assumptions about social identity sometimes contest them by using discourse conventions invested with quite different assumptions about social identities. Accordingly societal institutions are often sites of struggle between competing discourses "a cultural arena where ideological, discursive and social forces collide in 
an ever-unfolding drama of dominance and resistance" (Kumaravadivelu 1999: 475).

In terms of this explanation, social identity or "subjectivity" is multiple, a site of struggle, and changes over time (Weedon 1987). Each individual and each group have identities that are diverse, provisional, often overlapping and even contradictory because interlocutors position themselves and one another through their discourse as participants in a wide range of different and not necessarily compatible story lines. In discourses produced at various times and in various places their professional, ethnic, gender, generational, religious, or linguistic identities become more or less salient. As Davies and Harré (1990:46) put it, "the individual emerges through the process of social interaction, not as a relatively fixed end product but as one who is constituted and re-constituted through the various discursive practices in which they participate". They explain, moreover, that, in terms of this conception of social identity, the subject has agency. Though positioned in a particular way within a dominant discourse, a person may not take up this position, and indeed may contest it by developing quite different story lines i.e. using counter discourses that have implicit in them quite different assumptions about social identities.

\section{Contrasting discourses: \\ South Africa's language-in-education policies past and present}

In the period 1910-1994 language policy in South Africa was one of a formidable range of strategies both coercive and ideological through which the state maintained the hegemony of whites over blacks. It was informed by the ideology of the European nation state that assumes a natural division of humanity into nations whose unique identity is reflected in the language they speak. Implicit in this ideology is the myth that people live in single communities bounded in space and time and a "view of culture as a static phenomenon practiced uniformly and transmitted without change from generation to generation rather than dynamic and changing adaptations" (Goode and Schneider 1994:67). For the proponents of this ideology language diversity is a basis for conflict; a problem to be solved by promoting monolingualism. For reasons of political expediency the "solution" decided upon in South Africa was not monolingualism but limited bilingualism. Thus the 1910 Union constitution designated the two ex-colonial languages, English and Dutch, as the sole official languages and made no mention of indigenous African languages.

This policy ensured that native speakers of indigenous languages were marginalized. This is because a high level of proficiency in these two excolonial languages became a prerequisite for access to positions and services in most societal institutions e.g. higher education, the professions and the civil service. In judicial courts people who could not speak either English or Afrikaans were obliged to rely on the services of often poorly trained 
translators.

The language-in-education policy in period 1910-1930 allowed mother tongue instruction in English and Dutch (subsequently Afrikaans) in the elementary school, but since language education policy for Africans was not prescribed, by default the practice that had been established in African education before union, namely English as language of instruction, continued. After 1948 the Nationalist Government, in trying to consolidate Afrikaner hegemony, attempted to diminish the role of English. They did so by introducing mother tongue instruction in elementary schools for indigenous language speakers, and mother-tongue instruction in single-medium schools for English and Afrikaans speakers. Since mother tongue instruction is usually associated with multilingual policies, it is important to note that rather than a break with the ideology of European nation states this policy reflects an extreme version of it. Rather than opening up space for historically marginalized languages, it was a key strategy in the grand apartheid goal of final exclusion of speakers of such languages i.e. their location in separate, linguistic and culturally homogeneous "nation-states" or Bantustans.

Following the suggestion of Hornberger (2000) that language policies can be viewed as discourse, I suggest that together with a range of other pervasive and dominant discourses in that racist society, these policies helped construct a South African national identity as hegemonic, exclusive and conflicted.

By contrast South Africa's new multilingual policy is informed by a quite different assumption namely that language is a basic human right. The constitution requires that all people have the right to use the language of their choice, and that no person is discriminated against on grounds of language. It specifies that nine major indigenous African languages together with English and Afrikaans shall be official languages at national level, and that conditions shall be created for their development and for the promotion of their equal use and enjoyment. Further it calls for respect for and development of "non-official" languages such as Indian and European heritage languages.

The national language-in-education policy [Section 3(4) (m) of the National Education Policy Act (Act 27 of 1996) the National Education Policy Act (Act 27 of 1996)] is consistent with this national language policy. It requires the promotion of multilingualism through using more than one official language as the language of instruction, and the offering of additional languages as subjects. It also identifies additive bilingualism as the "normative approach" i.e. an approach that assumes that learners learn other languages (including dominant languages) most effectively when there is the continued educational use of the learners' first languages and, therefore, gives respect for the cultural assumptions and values implicit in them. The former Minister of Education (Statement 14 July 1997) explained that this policy is integral to the government's strategy of redressing the 
discrimination of the past and building a non-racial nation in South Africa i.e. of transforming society and creating a new South African identity. In his words: "Being multilingual should be a defining characteristic of being South African". He explained, further, that it "presupposes a more fluid relationship between languages and culture than is generally understood in the Euro centric model" and "accepts a priori that there is no contradiction in a multicultural society between a core of common cultural traits, beliefs, practices etc., and particular sectional or communal cultures".

Viewing these new policies as discourse I suggest that they, together with other discourses (in a range of societal institutions) that are congruent with them, have the potential to construct a truly multicultural South African identity i.e. one that is dynamic, overlapping, inclusive and egalitarian.

My reason for saying that it has the potential, is that the new policies have not entered a vacuum. In every institution there are presumably a range of discourses, some that are congruent with the new policies, and some with the old. Hornberger (2000) suggests that the ideological struggle is played out not just at the macro-level of policy discussion, but also at the micro-level of school discourses. Indeed she argues (2000:195) that because school discourses allow for the possibility of the construction of a wide range of multiple overlapping identities, it is at the micro level that the greatest hope for the construction of a national intercultural (multicultural) identity lies.

It is with this scenario in mind that I examine in some detail three of the discourses that were most pervasive in our data. Before I do so, though, I need to briefly share some information about the context and nature of the study.

\section{The context and nature of the study}

In 1999 we carried out fieldwork in six schools in the Durban metropolitan area of the KwaZulu-Natal province of South Africa using a combination of traditional and critical ethnographic approaches to data collection and analysis. Our general purpose was to investigate the extent to which the schools are promoting the multilingualism and multiculturalism advocated in the official language-in-education policy.

To provide some background, there were basically five racially-segregated schools systems in KwaZulu-Natal under the apartheid system one for the white communities (of a little over 500,000 people, according to the 1996 census), one for the Indian community (of almost 800,000 people), one for the so-called Coloured (or mixed-race) community (approximately 100,000 people), and two for the African community (approximately $7,000,000$ people). The available resources for the white schools far surpassed those of the black community in the townships and rural areas. The Indian and Coloured schools, while better funded than those of the black 
townships, still did not match those of the white community. Because of this historical advantage, schools in the former white communities have far better facilities and achieve dramatically better matriculation examination results than former Indian schools, Indian schools better than the Coloured schools, and the latter better than the African schools in township and rural areas. As a consequence, following the establishment of a single educational authority, there has been a major influx of African students into the Indian (and Coloured) schools located near African townships, and of many Indian students and some African students into former white schools. Since we assumed that the new multilingual/multicultural policy would have greatest appeal and best chance of success in schools that have multilingual/multicultural school populations, we focused on former white and Indian schools (2 high schools and one elementary school of each type) that have become dramatically more linguistically and culturally diverse following the desegregation of schools and other changes associated with the demise of apartheid. Incidentally, although the Indian community has experienced rapid language shift from (principally) Gujarati, Hindi, Tamil, Telegu and Urdu to English in the past 140 years, it remains itself culturally diverse. We did not examine African schools since, according to all available reports, their populations have remained relatively homogenous i.e. predominantly Zulu in language and culture. 98\% of the approximately seven million Africans in KwaZulu-Natal $(6,808,652)$ are Zulu native speakers according to the 1996 census.

Consistent with a traditional ethnographic approach to data collection and analysis, we used a wide range of data collection methods to collect rich and reasonably comprehensive data. These included written questionnaires to elicit demographic and other contextual information we asked the principals of schools to complete ahead of time. We did this so that the contextual information could inform our analysis of data collected by other methods including observation and audio recordings of English lessons and interviews with principals and teachers. We also collected documents that we suspected might give insights into the ethos of each school such as brochures for parents who might wish to enroll their children, school magazines, and codes of conduct. Our approach was ethnographic in the sense that we tried to get access to naturally occurring behavior by observing a variety of classes at the target schools. We asked principals if we could observe lessons with oral work in classes in which the degree of ethnic diversity matches or exceeds the average for the school as a whole. We also urged teachers not to prepare something special for the occasion.

Consistent with the ethnographic approach to data analysis, we attempted to be data-driven rather than hypothesis-driven, that is, we attempted as far as possible to let hypotheses, theories, and categories emerge from our analysis rather than impose them on the data. However, as Erickson (1986:143) points out, traditional ethnography is not radically inductive. We did, of course, bring preconceptions about what it would be 
important to focus on. However, we tried and succeeded in changing the lines of inquiry in response to changes in perception and understanding as our fieldwork progressed. Again consistent with traditional ethnography, we collected and analyzed concurrently, and our interpretations of data collected earlier guided our collection of subsequent data. We formulated questions relating to recurrent patterns of behavior that we felt might be important to understand and attempted to collect further data relevant to these. We also attempted to capture the participants' perspectives: their perceptions and understandings of what they were experiencing and related these constantly to our own, researcher's perspectives.

We departed radically from traditional ethnography in collecting and starting to process our lesson observation and interview data over a short period of time - just two weeks - to coincide with Sandra McKay's visit to South Africa. We also made use of data I collected independently earlier, as well as that collected by one of my graduate students (Khan ms) who was doing field work in two of those schools. Since we did not have more time for fieldwork it is possible that we may have focused too quickly, and, therefore, failed to capture data that might have yielded greater insights and better understandings.

Another aspect in which we departed from traditional ethnography, which we do not consider a limitation, is that, from the outset, we adopted a critical perspective. As May (1997), an advocate of critical ethnography, explains, traditional ethnographers' "concern with describing a social setting 'as it really is' assumes an objective, 'common-sense' reality where none exists. Rather, this 'reality' should be seen for what it is - a social and cultural construction, linked to wider power relations, which privileges some, and disadvantages other participants"(199). As will become evident, the notion that school practices and outcomes are socially constructed to serve the interests of some and at the expense of others strongly influenced both the questions we asked about our data and the interpretations and explanations we arrived at.

\section{The English-only discourse}

Given that the National Education Policy Act (Act 27) was promulgated in 1996 we assumed that progress towards multilingualism (or at least bilingualism) in desegregated schools in KwaZulu-Natal would be evident in increasing teaching/learning of Zulu, the L1 of approximately $80 \%$ of people in the province (Krige et al. 1994). We also assumed that in classrooms there would be considerable code switching between Zulu and English. We assumed that, since such behaviors are consistent with official policies, their desirability would be explicitly addressed or, at least, implicitly recognized in the discourses of administrators and teachers. In other words we assumed that what I term multicultural discourses would be pervasive if not yet dominant, and would provide a vehicle for teachers, 
administrators and learners to negotiate a more inclusive South African identity. Yet this is not what we found.

While multicultural discourses were evident in our data, we found that overwhelmingly participants were having to negotiate their identities within an English-only discourse. We used this term to suggest that it is very similar to discourse whose ideology and functions in other contexts have been extensively discussed (Auerbach 1993). Referring to the prevalence of English-only discourse in the USA, Auerbach (1993) contends that the English-only discourse is an example of covert ideological control since though "it has come to be justified in pedagogical terms ... it rests on unexamined assumptions, originates in the political agenda of the dominant group, and serves to reinforce existing relations of power" (12).

English-only discourse was particularly evident in our interviews with principals. With the exception of the principal of the former Indian elementary school, all principals explicitly rejected the use of Zulu in the classes other than in Zulu lessons. They also all indicated that code switching from English to Zulu is not permitted except in the playground or where, as some put it, the learners are "deficient" in English. They offered a range of reasons for their position. The principal of one former Indian high school contended that the promotion of English is consistent with the practices of the major political party of South Africa, the African National Congress $(\mathrm{ANC}),{ }^{2}$ of using English as a means of reconciling rival ethnic groups. This is at odds with the publicly stated position of the ANC. He contrasted his notion of ANC policy with the policy of the other major political party in the region, the Inkatha Freedom Party. He contended that Inkatha promotes the use of Zulu as a symbol of ethnicity, thus creating division within the region. This argument, of course, echoes those offered by the proponents of monolingualism in European nation states. We learnt in the interviews that English-only discourse occurs in a range of contexts of situation including those that are marked for institutional authority. For example, a principal of a former white high school told us that she informs the students and teachers at a school assembly at the beginning of the year that they must use only English in class. She argued that this policy is not discriminatory as it applies not just to Zulu but also to all the first languages of learners at the school. She apparently does not believe that, as the first language of $80 \%$ of the population of the province, Zulu should enjoy some priority. She explained that a further reason for prohibiting the use of Zulu

\footnotetext{
${ }^{2}$ The African National Congress (ANC) has been the governing party at national level since the advent of democracy in 1994. As such it is the chief architect of both the national language and language-in-education policies. In KwaZulu Natal province the ANC and the Inkatha Freedom Party (IFP) enjoy more or less equal electoral support, the IFP winning both the 1994 and 1999 elections by very narrow margins. Though the IFP has served and continues to serve in a government of national unity at national level, and though the ANC joined a provincial government of unity in 1999, there has been and continues to be fierce rivalry between the two parties. This has frequently spilt over into criminal acts of violence.
} 
is that occasionally Zulu-speaking learners use Zulu to insult adults and other learners. The principal of a former white elementary school gave another reason. He actively discouraged students from, as he put it, "reverting" to the use of Zulu because they need English for economic advancement.

The undisputed status of the ideological assumptions implicit in English-only discourse is evident in the low levels of provision for the teaching of Zulu in the six schools we visited. Zulu instruction is provided most fully at the former Indian elementary school where Zulu is taught as a subject in all grades. However, learners here are taught by teachers whose own preparation does not extend beyond twelve one-hour Zulu lessons. At one former white high school, Zulu is taught as a subject and is compulsory in grades eight and nine and is an option in grades ten to twelve. At the other former white school, Zulu is offered as an option from grades eight to twelve. However Zulu instruction is offered at neither of the former Indian high schools.

In sum, examination of data drawn from our discussions with school principals revealed that, despite multilingualism being official policy, English-only discourse is pervasive and enjoys institutional support at local level. English is represented as a unifying force; as a vehicle for economic advancement; and as the appropriate choice in prestigious domains such as the classroom. By contrast Zulu is represented as a potentially divisive force and as appropriate only for non-prestigious domains i.e. as more of a handicap than a resource. Learners who choose to use Zulu in class are represented as either rebellious or as deficient in English.

English-only discourse was very evident in our interviews with teachers as well. One of the teachers at a former Indian high school shared that she instructs her students not to use Zulu in class and that she will not let them explain things to one another in Zulu. She believes that if learners are to improve their English and be able to produce critical analyses in English, they must use English in class. In the words of another teacher "if Zulu speakers have chosen an English medium school staffed by native English speakers they must accept that Zulu will not be used in class." Some teachers also noted that the use of Zulu can be used a symbol of rebellion by Zulu speakers and that its use in the classroom can be threatening to teachers and to other non-Zulu speakers.

However, there was evidence in these interviews of a counter-discourse; a multicultural discourse that is congruent with the new national language policies. A number of teachers, primarily younger teachers, stated that they have discovered that the judicious use of Zulu in classrooms can be beneficial and are permitting the use of Zulu even when it runs counter to school policy. Thus, for example, the head of the English department at one former white high school and one of the teachers at a former white elementary school said that they encouraged the use of Zulu in group work.

In general, it seems clear that the teachers and administrators at the 
schools we visited are promoting extensive and, at times, exclusive use of English through English-only discourse. Viewed as an ideological strategy, such discourse naturalizes the use of English in prestigious domains. Thereby the school's personnel help maintain the hegemony of English in education and society generally. In terms of the assumptions implicit in this discourse, code switching is appropriate only in non-prestigious domains such as the playground or when learners are viewed as deficient in English. English-only discourse also constructs an identity for non-native speakers of English as language-deficient or rebellious and for the Zulu language as having low social and economic value. In other words, it stigmatizes Zulu and code switching between English and Zulu. By such strategic means English-only discourse helps maintain the existing power relationships, providing native speakers of English with a distinct advantage in the educational realm. Of more significance to the theme of this paper, this discourse reinforces the notion of South Africa's national identity as exclusive, hegemonic and conflicted.

\section{The decline of standards discourse}

A second discourse that was very pervasive was what we termed a decline of standards discourse. In this discourse administrators and teachers emphasized the need for maintaining the so-called canons, for upholding excellence, and for teaching good behavior or manners. A recurrent theme in the interviews was that standards of excellence in schools are being compromised during the process of desegregation. Many teachers and administrators argued that a major challenge facing schools is that critical thinking, moral values, and good manners have to be explicitly taught because schools can no longer rely on learners having been socialized into these in their families and communities. According to many teachers and principals these goals could be attained through the English curriculum. They explained that they often based their selection of topics and literary texts on their relative potential for promoting standards of excellence.

While a number of teachers stated that they valued English literature produced by African writers as a way of recognizing the multiculturalism of the school, some expressed concern that this might compromise the standards of excellence represented by the traditional canons of English literature. For example, one English teacher, who had been teaching at one of the former Indian high schools for fourteen years, said that integration had been a shock, and that although teachers want to treat all students equally, they found it difficult to teach typical curriculum materials like Shakespeare to students who do not speak English well.

Despite the pervasiveness of decline in standards discourse there was evidence in our data of a counter-discourse congruent with the new language policies. For example the head of the English department at one of the former white high schools had chosen Nervous Conditions by the Afri- 
can writer Tsitsi Dangarembga for the important matriculation examination rather than Hardy's Mayor of Casterbridge. She stated that she did not see this choice as a lowering of standards. As she put it, standards relate not to the choice of novel, but to the level at which you choose to teach it.

Moreover, although the discourse of learners was not the focus of our study, we found an interesting example of a learner using discourse to construct a wider, multicultural identity for herself. It occurred in a lesson of a young teacher in a former white high school. She was using a poem, the "Mantis" by Ruth Miller, one of the first published South African women poets. She pointed out that in the Zulu tradition there are many myths surrounding the mantis and called on one girl, presumably a Zulu speaker, to provide information on these myths. By supplying the information this student apparently accepted the teacher's positioning of her as someone with an intimate knowledge of traditional Zulu beliefs. However, I suggest that by describing what "they" believe she negotiated overlapping identities for herself i.e. not just a Zulu ethnic identity but identities in terms of other social categories - perhaps urban, educated, middle class. This was but one of a number of instances in our data that demonstrate that subjects have agency and that social identities are often co-constructed or negotiated.

The decline of standards discourse was evident also in the emphasis placed on the teaching of manners and the ways teachers subvert the goals of newly-introduced Outcomes-based materials. For example, in one grade 1 class the focus was on healthy foods. The teacher began the lesson by asking students why they should eat what she termed "good" food. Then she had students report what they had in their lunch boxes for that day. After advocating what she termed "good" foods such as vegetables and fruit, she suggested that "Some of you may not like what Mummy put in your lunch today," and asked them to draw what they wanted instead. It is significant to note that there was no reference to the ethnic foods of African and Indian students. She also informed us that she has added a unit on table manners to those prescribed because, as she put it, students are not getting such instruction at home.

Our data suggests that these teachers are not alone in their misinterpretation of the purpose of Life Skill units in the curriculum of the elementary schools. One finds a similar emphasis in some of the new Outcomes-based texts. For example, in Life Skills 1 (Lazenby et al 1998) there is a unit on "My School Family" in which there is a focus on rules. The activity begins with the teacher telling the students a story about a boy who always did exactly as he liked. He said, "Rules are for others, but not for me." One day he found he had no friends. Then the teacher is required to ask the children why they think he did not have friends and what they think the boy should have done. The activity ends by having the children draw up a list of rules they think they should have at school such as showing respect, being punctual, and being polite. The participation of the students in this final activity 
allows for a diversity of responses. However, nowhere in the materials do the authors alert readers to the possibility of considerable cultural diversity in what counts as respectful, punctual and polite. Nowhere do they alert them to the possibility of culturally diverse ways of expressing respect and politeness. It seems that in an era when the school personnel in general seem to think that standards are declining, the authors are using these materials for inculcating particular middle-class values. It is also important to note that even though the books were designed at a time when multicultural classrooms were increasing, the books give little attention to linguistic or cultural diversity. There is considerable irony in this since curriculum reform in terms of the outcomes-based model is intended by the ANC government as a major instrument for eliminating the inadequacies of education provided during the apartheid era.

To sum up, our findings suggest that the pervasive decline of standards discourse positions the canons and middle-class norms and ways of expressing these as markers of excellence, and other behaviors as threats to excellence. In other words, like English-only discourse, it serves both naturalizing and stigmatizing functions. By such means it helps maintain existing power relations providing those with an acquaintance with the cultural experience reflected in the canons and middle class norms with an advantage in the educational realm. Of more significance to the theme of the paper, it not only reduces the "space" for the expression, appreciation and development of cultural and linguistic diversity. It also reduces the opportunities for learners to co-construct a truly multicultural identity: one that is multiple, overlapping and changing; one in which, at different times and different places, different social categories (class, gender, generation, residence, recreational interests, religion) are salient.

\section{One-at-a-time discourse}

A final discourse that we observed as positioning students in the newly integrated schools of the Durban area is what we term one-at-a-time discourse. Lemke (1990) provides a clear account of one-at-a-time discourse and of the consequence of its widespread use in USA classrooms. Two interactional structures associated with one-at-a-time discourse that he examines in depth, and that occur with high frequency in our data, are teacher exposition and triadic dialogue. He explains that triadic dialogue has the familiar structure of three moves: the teacher initiates, learners respond, and the teacher evaluates their responses. Lemke argues that this involves a transposition of monologue (teacher exposition) into the mere appearance of true dialogue. When these two structures are frequently chosen classroom discourse takes on a one-at-a-time quality i.e. either the teacher or one of the students speaks at any one time, the teacher does most of the talking, and all student talk is channeled through the teacher.

Lemke (1990) acknowledges that teacher exposition and triadic dialogue 
(provided that the learners provide thematically correct answers) have some merit. They allow for the explicit teaching of the semantic relationships and thematic patterns of the academic content of the lesson. However, he argues that they do not provide the practice in speaking that learners require if they are to become fluent in the specialist language of the discipline. He argues, further, that triadic dialogues serve the interests of the teachers more than the learners. By choosing these structures teachers ensure that the discourse develops along predictable lines. This means that teachers are not asked unexpected questions and, therefore, are not faced with the challenge of relating the concepts to the common sense understandings of their learners.

Lemke explains that the failure of teachers to engage sufficiently with the learners' understandings is particularly disadvantageous to learners whose backgrounds are different from their own. In other words the use of one-at-a-time discourse has an ideological or gatekeeping function. It limits the numbers of people from historically marginalized groups who succeed in learning and getting access to further education and the careers that require this.

Elaborating further on the ideological function of one-at-a-time discourse, Lemke notes that learners are required to bid for turns, negatively sanctioned for calling-out, urged to wait until nominated, and discouraged from participating in side-talk with other learners (even though it often helps learners to relate their common-sense understandings to those of the teacher). Lemke argues that teachers and administrators police the conventions of one-at-a-time discourse in order to sustain the myth that learning is essentially an individual matter. This allows them to blame individuals for school failure rather than all the participants in the teaching/ learning process: learners, teachers, schools, education authorities, and parents. He adds that such policing advantages learners whose family and social background have prepared them for one-at-a-time discourse, and whose home cultures emphasize individual action without the support of others over collective or group activity.

Examination of our field notes revealed that although desks were clustered to allow for group work in as many as twelve of the seventeen classrooms we visited, group work occurred in only 6 lessons. Most teachers, moreover, spent a considerable part of class time socializing students to the one-at-time "rule".

For example in the former white elementary school we observed group work in one classroom only. Remarkably, since the size of classes is often given as a reason for not engaging in-group work, there are 37 learners in this grade two class. The teacher introduced the group task of determining where capital letters are required in a text as a detective game. She indicated that there were eight places in the text where capitals were required, and that the task was to determine where. She appointed a scribe and leader for each group and indicated where each group should work. It was evi- 
dent from the purposeful way in which the groups set about their task, that they were familiar with this way of proceeding. However the fact that she felt the need at the end of lesson to apologise to us for the noisiness of the class suggests that the choice of such discourse is marked or unconventional in this school.

This conclusion that one-at-time discourse is unmarked in this school is supported by the considerable time devoted in many of the other lessons we observed to instruction in the conventions of one-at-a-time discourse. For example, one of the teachers who had 30 grade one learners sitting on a carpet in front of her, spelt out explicitly both that one-at-a-time discourse is appropriate in class, and how this should be accomplished. For example, she informed them that they had to wait to be nominated before taking at turn:

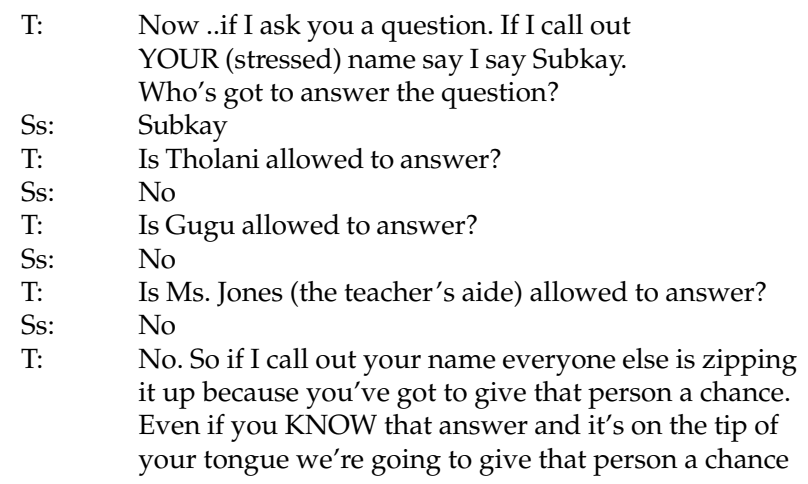

She also negatively sanctioned side-talk:

T: We have to listen because it's Debbie's turn. (at reading)

She stigmatized simultaneous talk by representing it as what immature people who are not ready for school do:

T: $\quad$ No, no Judith. No, no Judith. Judith. No. We're all doing this. (Putting her finger on her lips.). No no. Judith. Do this. I don't like to do this. I've not done this for a long time. You know that? Because you know who does this? Babies. Babies sit like this. When you were in pre-school didn't you have to sit just like this? No, no, no we can't talk if thirty or forty children are all talking at the same time....TALK ONE AT A TIME (slowly)

There was evidence, however, of a counter discourse in the former Indian elementary school. One of the few teachers who made use of group work explained that she started doing more group work since attending an Outcomes-Based Education (OBE) in-service workshop. She added that it is school policy to arrange learner's desks in clusters to facilitate group teaching consistent with OBE. She explained that what she sees as an advantage of group work is that quick progress can be made because the brighter and more fluent learners can explain to others exactly what is re- 
quired. She feels that group work succeeds when there is something to construct or when the learners have relevant knowledge. She added that when dealing with a new section of work she resorts to teacher-fronted teaching.

To sum up, there was clear evidence in our data that one-at-a-time discourse is pervasive in these schools and enjoys considerable institutional support. Such discourse constructs social identities for students familiar with it (mostly white and Indian middle-class) as competent, and for students who are not (mostly black African), as incompetent and, possibly, rebellious. As such, like English-only and decline-of-standards discourse, it helps maintain existing power relations. There was also evidence that the implementation of the new curriculum (OBE) is creating space for counter discourses in and through which the non-traditional intake of students can position themselves, their languages and cultural assumptions in a more positive way. However, in turn, this contesting is apparently being countered by the vigorous attempts to socialize such learners to dominant discourses and to police departures from it. We speculate that increasing cultural diversity in classrooms has made teachers feel an even greater need to engage in one-at-a-time discourse than they did before desegregation.

Of more significance to the theme of the paper, our findings suggest that one-at-time discourse severely restricts the opportunities for many learners to explore their own cultural experiences and meanings. As such it further reduces the opportunities of learners to negotiate a truly multicultural identity.

\section{Conclusion}

In general this study suggests that the schools we visited are sites of struggle between discourses that are congruent on the one hand with the discriminatory language policies of the past, and those that, on the other hand, are congruent with the current enlightened polices. It reveals that English-only, decline of standards, and one-at-a-time discourses are very dominant and serve ideological purposes. They, for example, marginalize students who do not speak English as a first language and who do not share middle-class values and middle-class ways of expressing them. They tend to construct an identity for them as language deficient and/or rebellious and/or unmannerly. As such they reinforce the view of South African national identity as hegemonic, exclusive and conflicted that has been constructed by the discriminatory policies of the past. The study also reveals that there are counter-discourses congruent with the discourse of South Africa's multilingual language policies. Such discourses, I have argued, provide opportunities for the participants to co-construct a truly multicultural South African identity, one that is multiple, dynamic and often overlapping.

In closing I turn to the significance of this study. It could be argued that 
since the study was of just six schools in one area of one province of South Africa, it has little significance beyond the schools themselves. Indeed, it could be argued that since English speaking whites and Indians together constitute only about $7 \%$ of the total population of 40 million people, what happens in schools that formerly catered for these groups exclusively would have little national significance even if it were possible to claim that the findings can be generalized to other such schools. While generalisation is clearly not possible I believe that there are reasons for arguing that the significance is greater than mere numbers would suggest. The most important of these reasons is that such schools are widely regarded as models for schools from other traditions to emulate. It follows that at very least the study should help people to question what is and is not worth emulating.

Rather than address that question I have chosen to speculate about answers to the more difficult question about what one can conclude from the study about the prospects of South Africans being able to construct a truly multicultural national identity.

As Pennycook (1999:335) observes, "critical analyses of social structure and the ways in which social relations may be culturally or ideologically maintained often tend to be pessimistic, deterministic, and reproductive, that is to say, they tend to suggest that people are trapped in unequal relations of power". And I acknowledge that it is easy in South Africa, now that the honeymoon period of South Africa's new democracy has passed, to interpret this study as further evidence that more things change, the more they remain the same. However there are a number of positive features that I wish to highlight.

The first is the space that South Africa's new language policies have opened up for the counter discourses that, though currently rather subdued, are evident in these schools. It is so much easier for one to contest the historical dominant discourses in these schools when the ideological assumptions implicit in ones counter discourse are congruent with those official policies. I also glean hope from the attitudes of the participants in these schools. It is possible that in exploring the ideological function of pervasive discourses in these schools what I have depicted is the desperate clinging to power at the micro level of a racist minority that at the macro level has lost most of its political power. Many of the assumptions implicit in these discourses are indeed racist, which should not surprise anyone since they became dominant in the apartheid era. However it may be that their pervasive use by teachers and administrators in these schools is related less to commitment to these assumptions and more to limited exposure to other discourses. What Sandra McKay and I were impressed by was the openness and trust shown by the teachers and administrators in giving us access to their classrooms and in sharing their perceptions with us. We were also impressed by their commitment to desegregated schooling and to the goal of quality education.

If I am correct in my assessment of the prospects for change then what I 
see as urgently required is for those in education to engage with multicultural discourses. It is here that I believe that politicians and academics have a particularly important role to play. One of the things that opened up space for multicultural discourse was the inclusivity that Nelson Mandela so often showed in his public utterances while President. Equally important I believe are empirical studies that have the potential to contest the assumptions implicit in dominant discourses. To be more specific I see an urgent need for studies of the sociolinguistic repertoires of speakers of indigenous language in South Africa along the lines of Zentella's (1997) study of code-switching amongst Puerto Rican children in New York or Rampton's (1995) study of "crossing" amongst adolescents of Anglo, AfroCaribbean and Indian descent in Britain. Since such studies would highlight the remarkable bilingual and multidialectal competencies of many indigenous speakers, they would inevitably contest the assumptions about the language deficiencies of indigenous speakers implicit in the dominant discourses examined in this study.

This observation about the research needed, allows me to make a connection with where I began this address. You will recall that I said that the hope Nessa and I shared was that our research would be useful to policy makers and ordinary citizens alike. It is my hope that this will be true of the study that I have reported on in this address today.

\section{References}

Auerbach, E. (1993). Re-examining English only in the ESL classroom. TESOL Quarterly, 27(1), 9-32.

Chick, J.K. (1985). The interactional accomplishment of discrimination in South Africa. Language in Society, 14(3), 299-326.

Davies, B. \& Harré, R. (1990). Positioning: The discursive production of selves. Journal for the Theory of Social behavior., 20(1), 43-63.

Erickson, F. (1986). Qualitative methods in research on teaching. In M.C. Wittrock (Ed.) Handbook of Research on Teaching (pp. 119-161). New York: Macmillan.

Fairclough, N. (1989). Language and power. London: Longman.

Gee, J.P. (1996). Social linguistics and literacies. London: The Falmer Press.

Goode, J. \& Schneider, J. (1994). Reshaping ethnic and racial relations in Philadelphia: Immigrants in a divided city. Philadelphia: Temple University Press.

Hornberger, N. (2000). Bilingual education policy and practice in the Andes: Ideological paradox and intercultural possibility. Anthropology and Education Quarterly, 31(2), 173-201.

Kumaravadivelu, B. (1999). Critical classroom discourse analysis. Special-Topic Issue: Critical Approaches to TESOL. TESOL Quarterly, 33(3), 453-484.

Khan, Y. (ms.) Multilingualism in education: A case study of two schools. Research in progress.

Krige, D., Dove, S., Makalima, B. \& Scott, D. (1994). The Education Atlas of South Africa. Durban: EGIS Unit of The Education Foundation.

Lazenby, B., Nmakola, N. \& Molopo, R. (1998). Life Skills 1. Pretoria: Kagiso Publishers.

Lemke, J. (1990). Talking science: language, learning and values. Norwood, N.J.: Ablex. May, S. (1997). Critical ethnography. In N. Hornberger \& C. Corson (Eds.) 


\section{Competing Discourses in South Africa}

Enclycopedia of Language and Education. Vol. 8: Research Methods in Language and Education (pp. 197-206). The Netherlands: Kluver Academic Publishers.

Pennycook, A. (1999). Introduction. Special-Topic Issue: Critical Approaches to TESOL. TESOL Quarterly, 33(3), 329-348.

Rampton, B. (1995). Crossing: Language and ethnicity among adolescents. New York: Longman.

Thompson, J. B. (1990). Ideology and modern culture: critical social theory in an era of mass communication. Cambridge: Polity Press.

Towards a National Language Plan for South Africa: Final Report of the Language Plan Task Group (LANTAG) Presented to the Minister of Arts, Culture, Science and Technology, Dr. B. S. Ngubane, August 8, 1996.

Weedon, C. (1987). Feminist practice and poststructuralist theory. Malden, MA: Basil Blackwell.

Zentella, A. C. (1997). Growing up bilingual. Malden, MA: Basil Blackwell.

\section{Acknowledgements}

Research for this paper was supported by grants from the Centre for Scientific Development and the University of Natal Research Fund. I also wish to thank Ralph Adendorff for his helpful comments on earlier versions. Most important I acknowledge the major contribution of Sandy McKay. The research on which paper is based was truly collaborative, so much so that it is difficult to separate out our individual contributions. This is why, as careful readers will have noted, I had such difficulty with choice of pronouns.

J. Keith Chick is Emeritus Professor in the Programme in Linguistics at the University of Natal, South Africa. He holds an M.A. in applied linguistics from Lancaster University (U.K.) and a Ph.D in sociolinguistics from the University of Natal. His specialist interests include interactional sociolinguistics, intercultural communication, language-in-education policy and planning, critical discourse analysis, and applied linguistics and language teaching. His writing in these areas has been published in edited volumes and in South African and international journals, including Language in Society and the Journal of Multilingual and Multicultural Development. 
Working Papers in Educational Linguistics 